Caris-Verhallen, W.M.C.M., Kerkstra, A., Bensing, J.M. Nurse-elderly patient communication in home care and institutional care. Patient Education and Counseling: 1998, 34(Suppl.1), S19

\begin{tabular}{|l|l|}
\hline $\begin{array}{l}\text { Postprint } \\
\text { Version }\end{array}$ & 1.0 \\
\hline Journal website & $\underline{\text { http://www.pec-journal.com/article/S0738-3991\%2898\%2990037-4/abstract }}$ \\
\hline Pubmed link & $10.1016 /$ S0738-3991(98)90037-4 \\
\hline DOI &
\end{tabular}

This is a NIVEL certified Post Print, more info at http://www.nivel.eu

\title{
Nurse-elderly patient communication in home care and institutional care
}

\author{
WiLma M.C.M. CARIs-VerhalLEN (A), AdA KeRKSTRA, JozIEN M. BENSING.
}

(a) Netherlands Institute of Primary Health Care ( NIVEL), PO Box 1568, 3500 BN Utrecht, The Netherlands.

Introduction. Previous research has shown that interpersonal communication between nurses and elderly patients is often superficial, task-related or inadequate because nurses show a tendency to take over care and responsibility. This study focuses on nurse-elderly patient communication in two different care settings: home care and a home for the elderly. Research question: Is there a general difference in nurses' important communication behaviour in the community or in a home for the elderly, as regards socioemotional communication and task-related communication?

Methods. In a sample of 181 nursing encounters, involving 47 nurses and 109 patients a study was made of videotaped nurse-patient communication. The video recordings were observed using an adapted version of Roter's Interaction Analysis System. The 23 verbal behaviours were reduced to five verbal categories, using correspondence analysis. For each encounter five summary statistics corresponding to these categories were calculated. To examine the communication in the two different care settings these statistices were analyzed using two way analysis of variance.

Results. Communication between nurses and elderly patients is characterized by socioemotional conversation to a large extent. Nurses in the home for the elderly show more social behaviour than nurses in home care, while nurses in home care show more often affective behaviour.

In home care nurses more often show verbal behaviour that structures the nursing encounter. The information exchange in home care is more often directed at topics relating the nursing activity and medical or therapeutic items, than in the home for the elderly care. The information exchange involving lifestyle and emotions is more determined by the type of care than by setting

Conclusions. The amount of socio-emotional interaction in both settings appeared to be higher than was reported in previous studies.

. Nurses in the home for the elderly frequently showed more social behaviour than nurses in home care.

. The adapted version of Roter's Interaction Analysis System has proven to be suitable for analysing nurse patient communication.

. In this study it was shown that video-taping is a feasible method in nursing research. 